\title{
THE INFLUENCE OF HYPEROXIA ON HEAT SHOCK PROTEINS EXPRESSION AND NITRIC OXIDE SYNTHASE ACTIVITY - THE REVIEW
}

\author{
Jakub Szyller $^{1)}$, Mariusz Kozakiewicz $^{2)}$, Piotr Siermontowski ${ }^{3)}$ \\ 1) DiaLab Medical Laboratories, Wrocław, Poland \\ 2) Department and Institute of Foodstuff Chemistry, the L. Rydygier Collegium Medicum, Bydgoszcz, Poland \\ ${ }^{3)}$ Military Institute of Medicine, Department of Marine and Hyperbaric Medicine, Gdynia, Poland
}

\section{ABSTRACT}

Any stay in an environment with an increased oxygen content (a higher oxygen partial pressure, $\mathrm{pO}^{2}$ ) and an increased pressure (hyperbaric conditions) leads to an intensification of oxidative stress. Reactive oxygen species (ROS) damage the molecules of proteins, nucleic acids, cause lipid oxidation and are engaged in the development of numerous diseases, including diseases of the circulatory system, neurodegenerative diseases, etc. There are certain mechanisms of protection against unfavourable effects of oxidative stress. Enzymatic and non-enzymatic systems belong to them. The latter include, among others, heat shock proteins (HSP). Their precise role and mechanism of action have been a subject of intensive research conducted in recent years. Hyperoxia and hyperbaria also have an effect on the expression and activity of nitrogen oxide synthase (NOS). Its product - nitrogen oxide (NO) can react with reactive oxygen species and contribute to the development of nitrosative stress. NOS occurs as isoforms in various tissues and exhibit different reactions to the discussed factors. The authors have prepared a brief review of research determining the effect of hyperoxia and hyperbaria on HSP expression and NOS activity.

Keywords: oxidative stress, hyperoxia, hyperbaria, heat-shock proteins, nitric oxide synthase.

ARTICLE INFO

PolHypRes 2017 Vol. 57 Issue 1 pp. 41 - 50

ISSN: $1734-7009$ eISSN: 2084-0535

Review article

DOI: $10.1515 /$ phr-2017-0030

Pages: 10, figures:0, tables:0

Submission date: $29.11 .2017 r$.

page www of the periodical: www.phr.net.pl

Acceptance for print: 08.03.2017r.

Publisher

Polish Hyperbaric Medicine and Technology Society 


\section{INTRODUCTION}

For millions of years an oxygen atmosphere has accompanied the majority of organisms inhabiting the Earth, thus ensuring their proper development and survival. However, oxygen has not always been present in the atmosphere in such a concentration as it is at present (20.95\%).

In the period of the paleoproterozoic an increase in its content was the cause of the so-called "great oxygenation event" leading, inter alia, to mass deaths of organisms unadjusted to the utilisation of this element in metabolic processes [1]. Currently, besides the tremendous positive role that oxygen and its compounds play in biochemical processes (e.g. cellular respiration [2], cellular signalling [3], immunological response [4]) it may contribute to the development of oxidative stress, particularly in conditions of an increased oxygen concentration (hyperoxia).

Such a condition is a result of a disturbed balance between pro- and antioxidative systems, i.e. the processes of generation of reactive oxygen species (ROS) and an organism's capability for their removal. Over the last two decades it has been one of the most interesting (and at the same time problematic) research topics for scientists all around the world. ROS react with all cell components: lipids, proteins, carbohydrates, nucleic acids [5]. This results in an occurrence of significant changes in the structure and biological function of cells.

In the case of proteins, oxidative damage often leads to a loss of biological activity [6]. In recent years, much attention has been paid to the role of heat shock proteins (HPS) in response to oxidative stress. These proteins, referred to as "protective" ones, are synthesised mainly as a result of an environmental stress (oxidative stress, trauma, hyperthermia, effect of toxins), but also in physiological conditions and play a key role in maintaining cellular homeostasis [7]. Among other things, they protect proteins against aggregation and take an active part in their adoption of a proper structure.

With regard to molecular mass HSPs may be divided into families: small HSP (sHSP, 16-30 kDa), HSP40, HSP60, HSP70, HSP90 and HSP110 (large HSP) [8]. The HSP70 protein family plays a fundamental role in the sorting of proteins, controlling their quality and sending damaged proteins to lysosomes or proteasomes [9]. It contains forms synthesised continuously and remaining under the influence of stress factors (inducible). Moreover, HSP70 indicate anti-inflammatory and anti-apoptotic activity [10]. Small HSP, HSP70 and HSP90 are located in cytoplasm, whereas HSP42 in mitochondria where it participates in the transporting of specific proteins to these organelles [11], where HSP10, HSP60 and HSP75 are also found [12].

Oxidative stress is inseparably connected with nitrosative stress, with the main role played by nitrogen oxide (NO). It is synthesised by nitrogen oxide synthase (NOS) as a result of L-arginine conversion to L-citrullin. Three synthase isoforms have been identified: neuronal (nNOS, NOS1), inducible (iNOS, NOS2) and endothelial (eNOS, NOS3) [13]. The reaction of superoxide anion radical $\left(\mathrm{O}_{2}{ }^{-}\right)$with nitrogen oxide leads to the creation of peroxynitrite (ONOO-) - one of the most important nitrating agents having an effect on protein functions.

The work involved a review of the research concerning the impact of oxidative stress on HSP and NOS expression in the conditions of hyperoxia, not only in blood serum but also in cells and tissues.

THE EFFECT OF HYPEROXIA AND HYPERBARIA AND HSPS AND NOS EXPRESSION

There is a limited number of available works concerned with the effect of hyperoxia/hyperbaria on the expression of heat shock proteins and NOS. And it is definitely the case that more studies refer to oxidative stress which is observed, inter alia, in the mentioned conditions.

\section{THE EFFECT ON HEAT SHOCK PROTEINS}

One of the studies which involved an exposure of a group of healthy volunteers (aged between 20-39 years, non-smokers) to hyperbaric oxygen (HBO) $(100 \%$ oxygen, 2.5 ATA, $3 \times 20 \mathrm{~min}$ ) revealed a significant increase of synthesis $(\mathrm{p}<0,01$, paired t-test) of inducible HSP72 form in lymphocytes 1 day after the exposure [14].

Ueng et al. studied the effect of $\mathrm{HBO}$ on chondrocyte apoptosis induced with nitrogen oxide (NO) and the role of HSP70 in this process [15]. The study evaluated the expression of HSP70, iNOS and caspase 3. In this paper the author presents only the results in relation to HSP70 and iNOS. The chondrocytes of rabbit joint cartilage were isolated and kept in a culture. Apoptosis was induced with the use of IL-1 $\beta$ generating NO synthesis.

Upon the lapse of 36 hours, the cells were divided into groups: control (C, $5 \% \mathrm{CO}_{2}, 95 \%$ of air), subjected to the activity of $100 \%$ oxygen at a regular pressure $(0,25 \mathrm{~min} 100 \%$ oxygen, next $5 \mathrm{~min}$. with $5 \%$ $\mathrm{CO}_{2}, 95 \%$ of air), subjected to the activity of hyperbaric air (HBA, 90 min. $5 \% \mathrm{CO}_{2}$, $95 \%$ of air, $2.5 \mathrm{ATA}$ ), subjected to the activity of hyperbaric oxygen (HBO, 25 min. 100\% oxygen, followed by $5 \mathrm{~min}$. with $5 \% \mathrm{CO}_{2}, 95 \%$ of air, 2.5 ATA).

An increased expression of HSP70 was noted in the group 0, HBA, HBO (with the respective HSP70/ $\beta$ actin ratio of: $45.4 \%, 49.5 \%, 65.6 \%$ in relation to control group $-29.8 \%$ ) and mRNA for HSP70. A rise in protein expression was also observed upon the lapse of 12 and 24 hours, also in the chondrocytes of animals subjected to the exposure of hyperbaric oxygen $(100 \%$ oxygen, 2.5 ATA, 1.5 hours a day 5 days a week. A significant drop in iNOS expression (the iNOS/ $\beta$-actin ratio) was noted in chondrocytes immediately following the exposures in all groups (O, HBA, HBO respectively: 53.1\%, 48.3\%, 18.8\%) in relation to the control group (64.0\%). Moreover, a decrease in mRNA for iNOS occurred. Similar relationships were observed after 12 and 24 hours [15].

The available publications concerning the role of HBO in decompression sickness (DCS) also indicate an effect of hyperbaria on HSP70. Xiao-Xiao et al. demonstrated a significant increase in HSP70 expression in spinal cord cells (mainly neurons) and pulmonary tissue (alveolar epithelial and endothelial cells) in rats with the peak occurring 18 hours from hyperbaric exposures (expressed as a HSP70/ $\beta$-actin ratio); a statistically insignificant expression increase ( $p>0.05$ ) was observed in the case of HSP27 and HSP90 [16].

The interval of markings was defined at 6 hours with the highest peak presumably falling around the 20th hour. The application of quercetin - an HSPs inhibitor, significantly reduced the effect of HBO. Quercetin 
participates in the modification of HSF-1 tertiary structures [17]. The authors indicate that an increase in HSP70 expression depends on NO (experiments were carried out with the use of an iNOS inhibitor). Simultaneously, NOS function is significantly influenced by HSP90 [18].

An interesting study was presented by Huang et al. regarding HBO effect on HSP32 expression [19]. It is an enzyme - heme oxygenase 1, participating in heme degradation to biliverdin, carbon monoxide (CO) and iron ions [20]. The authors subjected spinal neurons to the influence of hyperbaric oxygen for 60 minutes $(280 \mathrm{kPa}$, mixture with $1.79 \% \mathrm{CO}_{2}$ for the maintenance of $\mathrm{CO}_{2}$ partial pressure at $5 \mathrm{kPa}$ and the $\mathrm{pH}$ of cell cultures).

It was found that an increase in the levels of intracellular ROS and NO (immediately after hyperbaric exposure) as well as HSP32 expression was dependent on HBO. The application of a ROS scavenger (NAC, N-acetylcystein) significantly reduced the HSP32 expression. At the same time, it was found that pathways ROS/p38 MAPK/Nrf2 (p38 mitogen activated protein kinase/Nuclear factor-E2-related factor-2) and MEK1/2/Bach1 (mitogen-activated and extracellular signal-regulated kinase 1/2/BTB and CNC homology 1 as a negative regulation pathway) are engaged in the induction of HSP32 expression [19].

The authors of the study note that ROS (however not NO) are an important HSP32 inducing factor. Heme degradation products may reveal cytoprotective and antioxidant activity. It is also known that the HSP32/CO system may have an anti-inflammatory and anti-apoptotic effect [21]

Similar results concerning HSP32 were obtained by the authors in their previous study (with the peak occurring at the 12th hour), where a statistically insignificant increase in the expression of HSP27, HSP70 and HSP90 was observed [22].

\section{THE EFFECT ON NITROGEN OXIDE SYNTHASE}

[23] demonstrated the effect of HBO on the expression of various NOS isoforms in cochlea cells in guinea pigs, where nNOS and eNOS occur physiologically and iNOS is expressed under the influence of toxins, ischaemia or noise-induced hearing loss. It was found the particular NOS forms are expressed to a different degree in different parts of the cochlea. The researchers observed that following 20 HBO exposures only some regions were characterised by a significant increase in nNOS and eNOS expression (with the use of immunohistochemical staining). iNOS showed no differences in the expression prior to and following HBO application.

[24] Cabigas et al. presented results of an interesting work regarding the cardioprotective mechanisms induced by hyperoxia, hyperbaria and activating NOS. The studies were conducted on rats in the following conditions: hyperoxia $(100 \%$ oxygen) and normobaria (1 ATM), normoxia (21\% of oxygen) and hyperbaria (2 ATM), hyperoxia (100\% oxygen) and hyperbaria (2 ATM) for 1 hour. The control group consisted of animals exposed (also for 1 hour) to the conditions of normoxia ( $21 \%$ of oxygen) and normobaria (1 ATM).

The resistance of myocardial tissue to ischaemia was examined on an isolated heart model separated using the sternotomy technique. In order to see whether the cardioprotective mechanism is induced by NOS an NOS inhibitor was used - L-NAME. The evaluation of eNOS and HSP90 expression was performed with the use of the Western blot method with the use of myocardial tissue homogenate. The hearts of rats subjected to hyperoxia and hyperbaria were characterised by an increased eNOS expression.

At the same time, hyperoxia and hyperbaria caused a significant increase, by 4 times, in the activity of HSP90 and eNOS (protein-protein) in relation to the control group, without an increase of total HSP90 content. An analysis of nitrite $\left(\mathrm{NO}_{2}^{-}\right)$and nitrate content $\left(\mathrm{NO}_{3}{ }^{-}\right)$in myocardial tissue showed their significant increase, in the conditions of normoxia and hyperbaria, as well as hyperoxia and hyperbaria (by 2.2 and 2.3 times respectively, $p<0.05$ ). This correlates with an increase in NOS expression. L-NAME perfused hearts were characterised by a larger necrotic area resulting from the ischaemia (this did not concern only the normoxia and normobaria groups) in relation to control group.

NOS expression in brain tissue was similar. Chavko et al. describe a study regarding protein nitration and oxydation in hyperoxia conditions [25]. They subjected rats to hyperbaric exposures (5 ATM, time between 2 and 13 minutes or until an occurrence of characteristic changes in the EEG record caused by oxygen toxicity). The Western blot method was used to measure nitrotyrosine content in brain tissue homogenate following hyperbaric exposures. Nitrotyrosine (NT) is a marker of $0^{-00 \mathrm{NO}^{-}}$production (peroxynitrite, a significant nitrating agent). $00 \mathrm{NO}^{-}$ occurs in reaction with $\mathrm{NO}^{\bullet}$ (which in turn is produced by NOS) with superoxide anion radical $\left(\mathrm{O}_{2}{ }^{\circ-}\right)$, belonging to reactive oxygen species (ROS). NT content increased in every minute of the exposure and remained elevated upon its completion.

The use of 7-NI as a specific nNOS inhibitor led to a significant reduction of NO synthesis and NT production $(\mathrm{p}<0.05)$. At the same time the authors report that $\mathrm{NO}^{\bullet}$ reaction with $\mathrm{O}_{2}{ }^{--}$is one of the fastest reactions in which $\mathrm{NO}^{\circ}$ participates and leads to the creation of extremely reactive peroxynitrite [25]. Therefore, during HBO exposure the activity of NOS and generation of $\mathrm{NO}^{\circ}$ increases, thus resulting in an increase in NT content in the brain.

Baynosa et al. have presented results of interesting studies on animals concerning the mitigating impact of HBO on ischaemia-reperfusion effects with the presence of NO and being NOS-dependent [26]. The authors specified the following groups: early-phase group: non ischemic control, NIC, ischaeia-reperfusion group (4-hour ischeamiapa, 30-minute reperfusion, IR), ischaemia-reperfusion-HBO group (4-hour ischaemia, 30minute reperfusion, HBO during final 90 minutes of ischaemia, IR-HBO), NIC-HBO control group and latephase group: NIC, ischaemia-reperfusion group (4-hour ischeamia, 24-hour reperfusion, IR), ischaemiareperfusion-HBO group (4-hour ischaemia, 24-hour reperfusion and HBO during the final 90 minutes of ischaemia, IR-HBO). HBO: $100 \%$ oxygen, 2.5 ATA.

Ischaemia was induced by the clamping of the femoral artery and vein for a specified period of time, followed by release of the clamping in order to achieve reperfusion. In early-phase groups (30-minute reperfusion) no statistically significant differences in the expression of mRNA for NOS were noted in the gracilis muscle, rectus femoris muscle, artery, pulmonary tissue 
or between the groups. A statistically significant drop in mRNA NOS expression was observed in the artery in the IR-HBO group as compared to the NIC group. An increase of $120 \%$ in the expression of mRNA eNOS was noted in gracilis muscle in the IR-HBO group as compared with IR $(79.4 \pm 22.3$ vs. $36.1 \pm 4.5 ; \mathrm{p}<0.05)$. A $200 \%$ rise in the expression was observed in pulmonary tissues in IR-HBO with regard to NIC and IR $(91.0 \pm 31.2$ vs. $30.0 \pm 7.8$ and $30.2 \pm 3.1 ; \mathrm{p}<0.01$ ). The elevated mRNA expression resulted in a statistically significant eNOS protein expression indicated with the Western blot method. The authors did not demonstrate differences in iNOS expression in any of the groups [26].

Research material consisting of results from studies on blood serum are available. The studies conducted on professional military divers [27] indicated a high starting level of $\mathrm{NO}_{3}{ }^{-}$and a significant drop following a period of 6-weeks of diving activities $(49.61 \pm 19.86 \mu \mathrm{M}$ vs. $36.99 \pm 8.82 \mu \mathrm{M}, \mathrm{p}<0.05)$, which may point to a reduction in iNOS expression and activity in consecutive weeks of diving. There is also an opinion regarding iNOS synthesis inhibition due to the toxic effect of oxygen (hyperoxia in the course of diving). The authors of the above study also refer to the work where it was found that a significant increase in iNOS expression can occur after scuba diving [28].

\section{DISCUSSION}

\section{HEAT SHOCK PROTEINS}

The paper demonstrated the effect of hyperoxia and hyperbaric conditions on the expression of heat shock proteins and the activity of nitrogen oxide synthase in various tissues and blood serum. The effects of oxygen applied at a regular and increased pressure are different depending on cell and tissue (system) types. In all of the quoted studies an increase in the expression of various HSPs and NOS activity (and its particular isoforms) was observed, which was strictly related to the type of test material.

More research and results referring to a single specified type of cells or tissues are needed as well as marking of HSP expression, NOS activity in such tissues, comparisons with blood serum and times followed by parameter marking. Without such data it is extremely difficult to compare research results.

HSP are referred to as protective proteins. One of their roles consists in protecting cells against the harmful effects of oxidative (more precisely: reactive oxygen species) and nitrosative stress [29]. They are responsible for the link between the external environment and cells, they are located mainly intracellularly. Anti-apoptotic activity is characteristic of these polypeptides, which allows to increase cell survival under the influence of stressors [30].

To illustrate this, for instance, the expression of HSP90 occurs at a high level in normal conditions, i.e. physiological. That of HSP70, in turn, occurs upon activation of stress factors [31]. Hence the observed significant increase, for instance, in the expression of HSP70, HSP72 in hyperbaric conditions (quoted after $[14,15,16])$, where ROS generation and oxidative stress are intensified. This, on the other hand, or more precisely the level of reactive oxygen species, may lead to an activation of HSF1 (heat shock factor 1) inducing HSP gene transcription [32].
Such conditions lead to an occurrence of oxidative protein damage. HSP70 initiate the degradation of these molecules in proteasomes by recognising, joining a protein molecule and directing it towards $20 \mathrm{~S}$ proteasomes [33].

An increase in HSP70 expression in cells subjected to oxidative stress may reach over $200 \%$, whilst its inhibition leads to an accumulation of proteins with oxidative damage [33]. Reeg et al. also concluded that the inhibition of HSP70 expression does not result in changes in the formation of protein aggregates [33]. This is contradictory to numerous findings regarding the role of heat shock proteins (including the inhibition of an occurrence of denaturated protein aggregates, removal of denaturated polypeptides [34]), and may indicate that the HSP70 family does not participate in the aggregation prevention process.

HSP70 also take part in removing proteins through ubiquitination [35]. During oxidative stress, the maintenance of stability and integrity of $20 \mathrm{~S}$ proteasomes is also ensured by an involvement of HSP90; this relationship was described already in 1998 [36].

A significant increase in HSP70 expression was not observed in spinal neurons [19]. What is characteristic of nervous tissue is a high level of HSP70-2 (one of the representatives of the HSP70 subfamily revealing 84\% homology with HSP70-1a described in literature as HSP70/72) [34]. Perhaps, marking of an expression of a single specified protein (HSP70-2) would bring different results.

The authors of the study [16] did not show a statistically significant increase in HSP27 expression in spinal neurons. However, it needs to be emphasised that the said polypeptide counteracts an accumulation of damaged proteins in the nervous cells responsible for the development of neurodegenerative diseases [37]. Moreover, it reveals antioxidant activity, maintains glutation in a reduced form, thus contributing to a decrease in the level of free radicals [38].

The protection against oxidative stress and reactive oxygen species is also ensured by HSP32. Heme oxygenase removes heme from the reactive environment which has an effect on ROS generation in Fenton's reaction [39]; carbon monoxide, on the other hand, blocks $\mathrm{Fe}^{2+}$ oxidation, thus inhibiting prooxidative effects [40]. Nonetheless, it should be remembered that HSP32 may intensify ROS production caused by a high concentration of $\mathrm{Fe}^{2+}$ ions [20].

\section{NITROGEN OXIDE SYNTHASE}

Hyperoxia and hyperbaric oxygen lead to a reduction of iNOS expression in cartilage [15]. HSP70 protects chondrocytes from NO-induced caspase 3 activation [41] by revealing an anti-apoptotic effect.

The effect of hyperoxia and/or hyperbaria on nitrogen oxide synthase activity varies depending on enzyme isoform. We distinguish 3 isoforms: neuronal, inducible and endothelial (also called, in combination with nNOS - constitutive, cNOS). The inducible form is responsible for long-term synthesis of larger quantities of NO [42]. However the majority of presented studies show that an increased oxygen pressure and content in the breathing mix does not significantly influence iNOS expression in tissues.

It appears, however, that the situation may be different when it comes to blood serum/plasma $[27,43]$ and other tissues. Hyperoxia $\left(>95 \% \mathrm{O}_{2}\right)$ causes an 
increase of iNOS expression by 5 times and a double growth of eNOS expression in the pulmonary tissue in rats [44]. A rise in the expression of mRMA for iNOS, iNOS protein and nitrotyrosine concentration is also observed in the brain in conditions of an increased oxygen concentration [45].

Particular isoforms vary, inter alia, by structure, molecular mass and placement in the cell. The enzyme's task consists in nitrogen oxide (II) synthesis from the remaining nitric L-arginine. Nitrogen oxide fulfils significant functions in multiple life processes. Among other things, it is responsible for blood pressure regulation, blood platelets aggregation inhibition, neurotransmission, and many other. NOS overexpression, particularly the iNOS form, may be unfavourable for an organism, whereas high NO concentration may have a cytotoxic effect on cells [46].

Large amounts of NO may inhibit the flow of electrons in the respiratory chain and activate cyclooxygenase (COX), thus leading to the generation of reactive oxygen species [47]. The reaction of nitrogen oxide with superoxide anion radical (a reactive oxygen species occurring, inter alia, in the conditions of oxidative stress) leads to the creation of highly reactive and toxic peroxynitrite $\left(\mathrm{OONO}^{-}\right)$. Proteins affected by peroxynitrite may lose their specific characteristics and capabilities, e.g. catalytic. The amount of generated $\mathrm{OONO}^{-}$may be measured by the quantity of changed protein nitrotyrosine.

The available studies indicate that NO and NOS may play a significant role in the pathogenesis of oxidative lung damage by having both an adverse effect as well as that of minimising the organ's damage [48]. It is assumed that the exposure to high oxygen concentrations leads to an increase in NOS expression and NO activity (in pulmonary parenchyma particularly of eNOS). However, the effects of various oxygen conditions on NOS depends on the organ, enzyme form and locations of cells containing NOS in organs.

\section{BIBLIOGRAPHY}

1. Kopp RE, Kirschvink JL, Hilburn IA, Nash CZ. The Paleoproterozoic snowball Earth: a climate disaster triggered by the evolution of oxygenic photosynthesis. Proc Natl Acad Sci U S A. 2005 9;102(32):11131-6;

2. Gnaiger E, Steinlechner-Maran R, Méndez G, Eberl T, Margreiter R. Control of mitochondrial and cellular respiration by oxygen. J Bioenerg Biomembr. 1995;27(6):583-96;

3. Thannickal VJ, Fanburg BL. Reactive oxygen species in cell signaling. Am J Physiol Lung Cell Mol Physiol. 2000;279(6):1005-28;

4. Knight JA. Review: Free radicals, antioxidants, and the immune system. Ann Clin Lab Sci. 2000;30(2):145-58;

5. Phaniendra A, Jestadi DB, Periyasamy L. Free radicals: properties, sources, targets, and their implication in various diseases. Indian $\mathrm{J}$ Clin Biochem. 2015;30(1):11-26;

6. Neuzil J, Gebicki JM, Stocker R. Radical-induced chain oxidation of proteins and its inhibition by chain-breaking antioxidants. Biochem J. 1993;293:601-6;

7. Macario AJL, Conway de Macario E. Molecular chaperones: multiple functions, pathologies, and potential applications. Front Biosci 2007;12:2588-600:

8. Lindquist S. The heat-shock response. Annu. Rev. Biochem. 1986;55:1151-1191;

9. M.P. Mayer, B. Bukau, Hsp70 chaperones: cellular functions and molecular mechanism, Cell. Mol. Life Sci. 2005;62:670-684;

10. Tanaka K, Tanaka Y, Namba T, Azuma A, Mizushima T. Heat shock protein 70 protects against bleomycin-induced pulmonary fibrosis in mice. Biochem Pharmacol 2010;80:920-31;

11. Jee H. Size dependent classification of heat shock proteins: a mini-review. J Exerc Rehabil. 2016;12(4):255-9;

12. Xu Q. Role of heat shock proteins in atherosclerosis. Arterioscler Thromb Vasc Biol 2002;22:1547-1559;

13. Förstermann U, Sessa WC. Nitric oxide synthases: regulation and function. Eur Heart J. 2012;33(7):829-37;

14. Dennog C, Radermacher P, Barnett YA, Speit G. Antioxidant status in humans after exposure to hyperbaric oxygen. Mutat Res. $1999 ; 428$ $(1-2): 83-9$;

15. Ueng SW, Yuan LJ, Lin SS, Niu CC, Chan YS, Wang IC, Yang CY, Chen WJ. Hyperbaric oxygen treatment prevents nitric oxide-induced apoptosis in articular cartilage injury via enhancement of the expression of heat shock protein 70. J Orthop Res. 2013;31(3):376-84;

16. Ni XX, Ni M, Fan DF, Sun Q, Kang ZM, Cai ZY, Liu Y, Liu K, Li RP, Xu WG. Heat-shock protein 70 is involved in hyperbaric oxygen preconditioning on decompression sickness in rats. Exp Biol Med (Maywood). 2013;238(1):12-22;

17. Hosokawa N, Hirayoshi K, Nakai A, Hosokawa Y, Marui N, Yoshida M, Sakai T, Nishino H, Aoike A, Kawai K, Nagata K. Flavonoids inhibit the expression of heat shock proteins. Cell Struct Funct 1990;15:393;

18. Ghosh A, Chawla-Sarkar M, Stuehr DJ. Hsp90 interacts with inducible NO synthase client protein in its heme-free state and then drives heme insertion by an ATP-dependent process. FASEB J 2011;25:2049-60;

19. Huang G, Diao J, Yi H, Xu L, Xu J, Xu W. Signaling pathways involved in HSP32 induction by hyperbaric oxygen in rat spinal neurons. Redox Biol. 2016;10:108-118;

20. Loboda A, Jazwa A, Grochot-Przeczek A, Rutkowski AJ, Cisowski J, Agarwal A, Jozkowicz A, Dulak J. Heme oxygenase-1 and the vascular bed: from molecular mechanisms to therapeutic opportunities. Antioxid Redox Signal 2008;10:1767-1812;

21. S. Tsuchihashi, C. Fondevila, J.W. Kupiec-Weglinski, Heme oxygenase system in ischemia and reperfusion injury, Ann. Transplant. 9 (2004) 84-87;

22. Huang G, Xu J, Xu L, Wang S, Li R, Liu K, Zheng J, Cai Z, Zhang K, Luo Y, Xu W. Hyperbaric oxygen preconditioning induces tolerance against oxidative injury and oxygen-glucose deprivation by up-regulating heat shock protein 32 in rat spinal neurons. PLoS One. 2014;9(1):e85967;

23. Lin $\mathrm{CD}$, Wei IH, Lai $\mathrm{CH}$, Hsia TC, Kao MC, Tsai MH, Wu CH, Tsai MH. Hyperbaric oxygen upregulates cochlear constitutive nitric oxide synthase. BMC Neurosci. 2011;12:21;

24. Cabigas BP, Su J, Hutchins W, Shi Y, Schaefer RB, Recinos RF, Nilakantan V, Kindwall E, Niezgoda JA, Baker JE. Hyperoxic and hyperbaricinduced cardioprotection: role of nitric oxide synthase 3. Cardiovasc Res. 2006;72(1):143-51;

25. Chavko M, Auker CR, McCarron RM. Relationship between protein nitration and oxidation and development of hyperoxic seizures. Nitric Oxide. 2003;9(1):18-23;

26. Baynosa RC, Naig AL, Murphy PS, Fang XH, Stephenson LL, Khiabani KT, Wang WZ, Zamboni WA. The effect of hyperbaric oxygen on nitric oxide synthase activity and expression in ischemia-reperfusion injury. J Surg Res. 2013;183(1):355-61;

27. Alcaraz-García MJ, Albaladejo MD, Acevedo C, Olea A, Zamora S, Martínez P, Parra S. Effects of hyperoxia on biomarkers of oxidative stress in closed-circuit oxygen military divers. J Physiol Biochem. 2008;64(2):135-41;

28. Ferrer, M.D., Sureda, A., Batle, J.M., Tauler, P., Tur, J.A., Pons, A. Scuba diving enhances endogenous antioxidant defenses in lymphocytesand neutrophils. Free Radic Res, 2007,41:274-281;

29. Kalmar B, Greensmith L. Induction of heat shock proteins for protection against oxidative stress. Adv Drug Deliv Rev. 2009;61(4):310-8;

30. Kaźmierczuk A. Kiliańska ZM. Plejotropowa aktywność białek szoku cieplnego. Postepy Hig Med. Dosw. 2009;63:502-521;

31. Takayama S, Reed J, Homma S. Heat-shock proteins as regulators of apoptosis. Oncogene 2003;22:9041-9047;

32. Powers MV, Workman P. Inhibitors of the heat shock response: biology and pharmacology. FEBS Lett 2007;581:3758-3769;

33. Reeg S, Jung T, Castro JP, Davies KJ, Henze A, Grune T. The molecular chaperone Hsp70 promotes the proteolytic removal of oxidatively damaged proteins by the proteasome. Free Radic Biol Med. 2016;99:153-166;

34. Daugaard $M$, Rohde $M$, JäätteläM. The heat shockk proteinę 70 family: Highly homologous proteins with overlapping and distinct functions. FEBS Lett 2007; $581: 3702-3710$; 
35. S.H. Park, N.Bolender, F.Eisele, Z.Kostova, J.Takeuchi, P.Coffino, et al. The Cytoplasmic Hsp70 chaperone machinery subjects misfolded and endoplasmic reticulum import-incompetent proteins to degradation via the ubiquitin-proteasome system. Mol. Biol. Cell 2007,18(1):153-165;

36. M. Conconi, I.Petropoulos, I.Emod, E.Turlin, F.Biville, B.Friguet, Protection from oxidative inactivation of the $20 \mathrm{~S}$ proteasome by heat-shock protein 90. Biochem. J. 1998,333:407-415

37. Laskowska E. Small heat shock proteins - their role in apoptosis, carcinogenesis and diseaes connected with protein aggregation. Post. Biochem. 2007;53:19-26

38. Arrigo AP, Virot S, Chaufour S, Firdaus W, Kretz-Remy C, Diaz-Latoud C. Hsp27 consolidates intracellular redox homeostasis by upholding glutathione in its reduced form and by decreasing iron intracellular levels. Antioxid Redox Signal. 2005;7:414-422;

39. Seixas E, Gozzelino R, Chora A, Ferreira A, Silva G, Larsen R, Rebelo S, Penido C, Smith NR, Coutinho A, Soares MP. Heme oxygenase-1 affords protection against noncerebral forms of severe malaria. Proc Natl Acad Sci USA 2009;106:15837-15842

40. Pamplona A, Ferreira A, Balla J, Jeney V, Balla G, Epiphanio S, Chora A, Rodrigues CD, Gregoire IP, Cunha-Rodrigues M, Portugal S, Soares MP, Mota MM. Heme oxygenase-1 and carbon monoxide suppress the pathogenesis of experimental cerebral malaria. Nat Med 2007;13:703710 ;

41. Arai $\mathrm{Y}$, Kubo $\mathrm{T}$, Kobayashi $\mathrm{K}$, et al. Adenovirus vector mediated gene transduction to chondrocytes: in vitro evaluation of therapeutic efficacy of transforming growth factor beta 1 and heat shock protein 70 gene transduction. J Rheumatol 1997;24:1787-1795;

42. Lechner M., Lirk P., Rieder J.: Inducible nitric oxide synthase (iNOS) in tumor biology: the two sides of the same coin. Semin. Cancer Biol. 2005;15:277-289;

43. Ferrer, M.D., Sureda, A., Batle, J.M., Tauler, P., Tur, J.A., Pons, A. Scuba diving enhances endogenous antioxidant defenses in lymphocytesand neutrophils. Free Radic Res, 2007,41:274-281;

44. Potter CF, Kuo NT, Farver CF, McMahon JT, Chang CH, Agani FH, Haxhiu MA, Martin RJ. Effects of hyperoxia on nitric oxide synthase expression, nitric oxide activity, and lung injury in rat pups. Pediatr Res. 1999;45(1):8-13;

45. Hoehn T, Felderhoff-Mueser U, Maschewski K, Stadelmann C, Sifringer M, Bittigau P, Koehne P, Hoppenz M, Obladen M, Bührer C. Hyperoxia causes inducible nitric oxide synthase-mediated cellular damage to the immature rat brain. Pediatr Res. 2003;54(2):179-84;

46. Moncada S., Higgs A.E. The L-arginine-nitric oxide pathway. N. Engl. J. Med. 1993;329:2002-2012

47. Sokołowska M, Włodek L. Dobre i złe strony tlenku azotu. Folia Cardiol 2001;8(5):467-477;

48. Xu F, Tai Fai F, Yung E, Yang M, A YIN J. Endothelial and inducible nitric oxide synthase gene and protein expression in hyperoxia-induced lung injury in premature rat. Acta Pharmacol Sin 2002;(23 Suppl):52-58.

Jakub Szyller

DiaLab Medical Laboratories

Życzliwa 15-17, 50-001 Wrocław 